Revista de la red interuniversitaria de estudios sobre las literaturas rioplatenses contemporáneas en Francia

$9 \mid 2013$

Homenaje a Ana María Barrenechea

\title{
Dar el salto. Los comienzos de Rayuela
}

Julio Premat

\section{OpenEdition \\ Journals}

Edición electrónica

URL: http://journals.openedition.org/lirico/1157

DOI: $10.4000 /$ lirico.1157

ISSN: 2262-8339

Editor

Réseau interuniversitaire d'étude des littératures contemporaines du Río de la Plata

Referencia electrónica

Julio Premat, « Dar el salto. Los comienzos de Rayuela », Cuadernos LIRICO [En línea], 9 | 2013, Puesto en línea el 01 septiembre 2013, consultado el 19 abril 2019. URL : http://journals.openedition.org/ lirico/1157 ; DOl : 10.4000/lirico.1157

Este documento fue generado automáticamente el 19 abril 2019.

\section{(c) $(1) \Theta \Theta$}

Cuadernos LIRICO está distribuido bajo una Licencia Creative Commons Atribución-NoComercialSinDerivar 4.0 Internacional. 


\title{
Dar el salto. Los comienzos de Rayuela
}

\author{
Julio Premat
}

\section{Un regalo}

1 “Te prometí este cuaderno de trabajo y aquí te lo lleva Eduardo. No vale nada, pero me gusta pensar que lo vas a guardar vos, que tan cerca has estado siempre de mis libros y de mi afecto" (Cortázar 2012 : 424). Con esas palabras el escritor acompaña un regalo hecho a Ana María Barrenechea en agosto de 1963. Es un cuaderno prometido ya antes del envío, un cuaderno de anotaciones generales usado como apoyatura y guía para la escritura de Rayuela, novela cuyo primer ejemplar llega a las manos del autor a fines de julio (Barrenechea, en el momento en que descubre y estudia la crítica genética, lo va a publicar, precedido de un sólido estudio genético, bajo el título de Cuaderno de bitácora de Rayuela, en 1983). Un par de meses después, en octubre, Cortázar contesta, exaltado, a una carta en la que la crítica da cuenta de su impresión, muy positiva, a la primera lectura de la novela, carta que por lo tanto no contiene las reservas que había despertado en ella Los premios; lo hace dándole un relieve particular a la aprobación de Barrenechea : “[...] vos, tan serena y segura en tus juicios, vos me escribís una carta que es como una respiración profunda, que está llena de rumores y cosas apenas dichas...." (434). De manera especular Barrenechea utiliza, pareciera ser, el tono en que el libro está escrito. Cortázar también evoca y justifica entonces el regalo hecho unas semanas atrás :

Cuando te mandé el cuaderno, lo hice porque nadie podía tener más derecho que vos a leerlo ; pero al mismo tiempo me entristecía presentir que Rayuela no te iba a gustar nada, y que el cuaderno no pasaría de un testimonio de afecto y, quizá, de una curiosidad bibliográfica por así decir. (434)

2 Temores sin fundamento : Barrenechea elogia con entusiasmo el libro y Cortázar siente que los puentes, que se habían roto con ella, están tendidos otra vez. De lo que se trata es, no sólo de una "alegría" "hermosa" y "libre de todo narcisismo", sino ante todo de una "reconciliación" que "es alta y es maravillosa, porque es una reconciliación difícil y arriesgada, donde yo he jugado todas mis cartas, las buenas y las malas, y vos has distinguido entre unas y otras" (435). Nótese de paso (la constatación tiene su 
importancia) que el autor utiliza a menudo una retórica casi amorosa en respuesta a lecturas positivas por parte de quienes le merecen respeto y confianza. A Fernández Retamar le transmite en agosto del 64 su alegría de que un poeta como él "haya encontrado en Rayuela todo lo que yo puse o traté de poner, y que el libro haya sido un puente entre tú y yo y que ahora, después de tu carta, yo te sienta tan cerca de mí y tan amigo"; afirma inclusive extrañarlo y querer hablar de verdad con él de tantas cosas, lo que sería posible, a pesar de ser "muy tímido", porque "con ustedes, los cubanos, yo me desnudo como frente al mar" (563).

3 La promesa del regalo y su cumplimiento, tan sorprendentemente prematuros y que formarían parte de las "cartas" jugadas por Cortázar para despertar la aprobación de la crítica, era entonces un intento de restaurar puentes, de reconciliar juicios, como si la exhibición del proceso de escritura tuviera la capacidad de influir en la opinión sobre el libro terminado. Más allá del gesto de seducción que implica el envío del cuaderno, él parece pensar que hay algo suplementario que mostrar: los entretelones de su trabajo, las etapas de gestación y textualización, la intimidad de su yo escritor son elementos que deberían permitir una recepción más adecuada y positiva de la novela. En los hechos Barrenechea recibe, con muy poco tiempo de intervalo, el libro editado y el cuaderno, lo que la invita a una lectura insólita: la de ambos textos en paralelo. 0 , si se quiere, el escritor pone en circulación, simultáneamente aunque en esferas diferentes, los dos textos.

4 La anécdota del regalo del cuaderno y esta relación hecha de una proximidad en libros y afectos, leídas junto con el conjunto de ediciones de materiales genéticos posteriores, declaraciones del autor y textos varios que rodean a Rayuela, permiten identificar las etapas de un relato sobre la emergencia de la novela, relato que participa en su extraordinaria recepción. Y no sólo: el relato es también un mojón importante en la definición narrativa y cambiante de una figura de autor. Es sabido que la trayectoria de Cortázar se acompaña de una serie de hitos y episodios claves que van delineando a un personaje múltiple : el misántropo lector "exiliado" en ciudades del interior argentino, la entrada en la literatura después de la expulsión de "Casa tomada" y la obtención de una madurez y perfección formal ;la partida "antiperonista" del 51 que coincide con la publicación de Bestiario (la partida es, entonces, simultánea a un inicio en el campo literario), la transformación existencial, lúdica y estética que se produciría entre "El perseguidor" y Rayuela, pasando por Los premios y por la aparición de los cronopios, y al final el camino de Damasco de la conversión revolucionaria, hecha del viaje a Cuba y del compromiso público, en particular con Nicaragua.

5 Por otro lado y entre muchos otros aspectos las cartas, el cuaderno editado, los estudios de Barrenechea, e inclusive las numerosas declaraciones posteriores de Cortázar, apuntan enfáticamente a un momento nodal y enigmático, el comienzo de la escritura, el origen, el "punto de arranque", utilizando una expresión del propio autor. El relato gira alrededor de ese momento, hacia él apunta, buscando fijar un espacio de determinación y definición que es indispensable para articular cualquier narración consecuente sobre el proceso. También, se enmarca paradójicamente la novela con una fuerte intencionalidad, en contradicción con algunos de sus postulados explícitos y con lo que puede saberse o pensarse del proceso de escritura tal cual, quizás, se produjo.

6 En lo que sigue intentaré comentar el relato del origen de Rayuela, sin pretender proponer una versión alternativa sino, al revelar los alcances de las diferentes opciones, subrayar las funciones y valores que se le atribuyen al comienzo, inevitablemente legendario. El 
ejemplo lleva a ampliar la perspectiva, planteando la problemática del inicio de la obra, de su determinación subsiguiente a partir del primer gesto, palabra o idea, de sus variantes, de su instrumentalización. Más que completar un análisis genético tradicional, se trata de intentar ver en ese relato de origen, los avatares de una figura de autor, la interacción de ésta con la recepción de la obra y el valor de la edición de materiales genéticos en términos simbólicos, estéticos, imaginarios y no estrictamente documentales.

\section{Del arranque al origen}

7 Durante el período 1958-1963 Cortázar comenta abundantemente la escritura de una novela, proyectada o en preparación, comentarios que en buena medida encuentran ecos en las teorías literarias expuestas en Rayuela y en particular en las "Morellianas". La visión dada es la de un proyecto impreciso y ambicioso, que se escribe buscando la idea general, la estructura, la lógica del conjunto, es decir un movimiento de redacción que se sitúa fuera de todo programa :

Quiero escribir otra [novela], más ambiciosa, que será, me temo, bastante ilegible ; quiero decir que no será lo que suele entenderse por novela, sino una especie de resumen de muchos deseos, de muchas nociones, de muchas esperanzas y también, por qué no, de muchos fracasos. Pero todavía no veo con suficiente claridad el punto de arranque (178).

8 Hay entonces un deseo de novela (Barthes 183-200), la energía del comenzar (Said 34), sin una puerta de entrada definida ni una forma establecida: el proyecto parece ser ese escribir el deseo, esa situación, y no un resultado (considerado, entonces, "bastante ilegible"). Otro comentario, en una carta de mayo de 1960, cuando la escritura ya está en camino, retoma el carácter múltiple del comienzo : "No sé lo que va a salir de una larga aventura a la que creo aludí en alguna otra carta. No es una novela, pero sí un relato muy largo que en definitiva terminará siendo la crónica de una locura. Lo he empezado por varias partes a la vez", y luego comenta que escribe a menudo el final antes del principio, y al redactar luego el inicio tiene que recomenzar lo ya hecho, o bien que escribe dos veces episodios con los mismos personajes, todo lo cual le daría al proceso de escritura las características tópicas de la escritura por impulso, (216, cf. Constantin 40-41, De Biasi 33-35).

9 Nótese que las afirmaciones de las cartas (como luego las de las entrevistas y otros escritos similares), se asemejan al discurso de Morelli y a las reflexiones de Oliveira dentro de la novela, en particular las representaciones autorreflexivas y metaliterarias de la escritura, de sus motivaciones y sus objetivos. Por ejemplo el capítulo 82, que da la misma visión de la creación de la que leemos en la correspondencia de Cortázar :

Morelliana

¿Por qué escribo esto ? No tengo ideas claras, ni siquiera tengo ideas. Hay jirones, impulsos, bloques, y todo busca una forma, entonces entre en juego el ritmo y yo escribo dentro de ese ritmo, escribo por él y no por eso que llaman el pensamiento y que hace la prosa, literaria $u$ otra. Hay primero una situación confusa, que solo puede definirse en la palabra; de esa penumbra parto, y si lo que quiero decir (si lo que quiere decirse) tiene suficiente fuerza, inmediatamente se inicia el swing... (330)

Se utiliza así un tono reconocible, a la vez ficticio, vehemente y con una gran capacidad de crear una proximidad afectiva o un "puente" con el lector. Rayuela inventa una voz de autor, y por lo tanto un personaje de autor, que va a recorrer al mismo tiempo la obra y 
las intervenciones de Cortázar, borrando la frontera entre lo literario y lo metaliterario, entre la ficción y la intimidad. Rayuela transforma al escritor en personaje, y no sólo por la dimensión autoficcional de Morelli.

Por otro lado, Cortázar se dice consciente durante la escritura de estar intentando algo diferente, o en todo caso de pelear con las propias tradiciones: la de los cuentos fantásticos, la de sus novelas precedentes, la del género en general. En las cartas la idea del cambio es insistente : la emergencia del proyecto de Rayuela está aureolado, embebido por ese deseo de escribir lo otro, pero también de ser otro. Cambio que se cristaliza en la exaltación suscitada por una libertad narrativa y por una especie de explosión de posibilidades. Por ejemplo, una carta del 27 de junio del 59 : “¿Cómo escribir una novela cuando primero habría que des-escribirse, des-aprenderse, partir à neuf, desde cero, en una condición pre-adamita, por decirlo así ?" Por ende, las herramientas utilizadas en los cuentos ya no sirven: "Un cuento es una estructura, pero ahora tengo que desestructurarme para ver de alcanzar, no sé cómo, otra estructura más real y verdadera" ; de lo ya escrito, sólo "El perseguidor" es diferente : "Ahí andaba yo buscando otra puerta. Pero todo es tan oscuro, y soy tan poco capaz..." (188). Notar por lo tanto que la gran reorientación supuesta por "El perseguidor" (según sus declaraciones posteriores) es ya explícita en esa época. Por otro lado, a la voluntad de radicalidad se la enfatiza : “[...] nunca se escribió un libro tan a contrapelo, tan a contralibro" (337) ; “[...] en Rayuela he roto tal cantidad de diques, de puertas, me he hecho pedazos a mí mismo de tantas y de tan variadas maneras. [...] Tengo la impresión de haber ido hasta el límite de mí mismo, y de que sería incapaz de ir más allá" (394).

Es decir que el escritor presupone una reorientación desde el comienzo de los tiempos (preadamita), lo que exige una deconstrucción, una autodestrucción, una regresión hacia lo arcaico, para recomenzar el tiempo en otra dirección. Se trata de una novedad heroica y ardua (búsqueda de una puerta en la oscuridad, llegada hasta los límites, creación de lo nunca escrito). Lo entrevisto es un texto fuera de todo lo conocido, libro total o libro ideal capaz de recomponer los pedazos de un escritor más allá de sus fronteras, más allá de lo pensable (Gunn 65). La intención es ésa -retomar la saga vanguardista de la gran ruptura, de la metamorfosis total-, sin que el camino a seguir para lograrlo se vislumbre todavía.

En todo caso, el relato sobre "El perseguidor" como precedente, Los premios como pasaje y Rayuela como revolución copernicana, vuelve de manera sistemática en este período y en el resto de la vida de Cortázar : forma parte de un episodio de refundación por parte de un autor maduro y tardío en su evolución. En paralelo a este cambio y a esta redefinición de su perfil, escribe los textos sobre los cronopios y empieza a utilizar, sistemática e insistentemente, la idea de un "escritor-cronopio" en cartas, declaraciones y textos varios: después de la seriedad del autor de los cuentos, se impone la construcción voluntarista del homo ludens como identidad y como posición digamos metafísica. Los dos fenómenos (ruptura anunciada por "El perseguidor", irrupción del humor absurdo aglutinada en un tipo literario) se dan al mismo tiempo. También habría que notar la aparición, desde 1963, de lo que cabe denominar un "mitema", la recepción entusiasta de los jóvenes, que Cortázar ya menciona en octubre de 1963 (dice en una carta a Barrenechea que muchas reacciones de jóvenes a Rayuela le "bastarían" para sentirse "justificado como escritor" y le prueban que el libro es un "feroz sacudón" necesario) (434) y en muchas otras cartas del mismo período. No deja de repetir a lo largo de los años el "asombro" que le produce descubrir ese fenómeno. ${ }^{1}$ La idea del cambio y de la novedad se cristaliza en una imagen de juvenilismo y de la ruptura generacional, en la cual se 
incorpora rápidamente al propio Cortázar (del que se decía, por ese entonces, que no envejecía, con su aspecto de eterno adolescente y luego con su desaliñada barba).

Diez años después, en 1973, el autor publica, en un número especial de la Revista Iberoamericana dedicado a su obra y en particular a la novela, un capítulo inédito que debía llevar el número 126 y que no fue incluido en la edición definitiva. El texto se intitula "La araña" y narra un extraño ritual sexual entre Talita y Traveler, de tonalidades sádico masoquistas, en el cual el hombre instala hilos que asocian diferentes puntos de una habitación con el cuerpo de la mujer, poseída violentamente al final del texto. Se trata, según Cortázar, del primer capítulo escrito, tal cual lo aclara en una nota introductoria, justificando al mismo tiempo su exclusión :

Rayuela partió de estas páginas; partió como novela, como voluntad de novela, puesto que existían ya diversos textos breves (como los que dieron luego los capítulos 8 y 132) que estaban buscando aglutinarse en torno a un relato. Sé que escribí de un tirón este capítulo, al que siguió inmediatamente y con la misma violencia el que luego se daría en llamar "del tablón" (41 en el libro). Hubo así como un primer núcleo en el que se definían las imágenes de Oliveira, de Talita y de Traveler ; bruscamente el envión se cortó, hubo una penosa pausa, hasta que con la misma violencia inicial comprendí que debía dejar todo eso en suspenso, volver atrás en una acción de la que poca idea tenía, y escribir, partiendo de los breves textos mencionados, toda la parte de París. (Cortázar 2009 : 171)

Aunque Rayuela haya sido escrita de manera caótica, incierta, y aunque el proyecto en sí de la novela sólo haya surgido al final, el gesto supone que en 1973 es importante hacerle la pregunta del inicio o la del origen, en el sentido legendario del término. Más que del comienzo de la redacción (los textos más viejos son esos fragmentos descriptivos breves de 1951 sobre París a los que alude Cortázar), de lo que se trata es de hallar y mostrar un comienzo radical, el paso de la nada, del no proyecto, a la escritura en movimiento. "La araña" cumple esa función (es el primer texto en que Rayuela sería, ya, Rayuela). En una operación de autocelebración y en el momento de cumplir diez años la edición prínceps, Cortázar "prolonga" el texto édito (como se publican a menudo de manera póstuma los textos desechados por un escritor exitoso) y realiza una divulgación pública de dos elementos esenciales : el punto de partida y un documento genético, es decir, una primera edición de huellas del proceso de redacción. Lo que repite lateralmente el regalo a Barrenechea del Cuaderno de bitácora y acentúa el carácter de patchwork y la dimensión metaliteraria de Rayuela, así como anuncia la profusa serie de inéditos que se publicarán al final de su vida y después de su muerte. Al dar a conocer "La araña" y al ubicar a ese fragmento en el lugar determinante del comienzo, Cortázar sacraliza su propio texto y establece un orden más tradicional de creación. Todo lo cual, quiérase o no, contradice las primeras formulaciones del proyecto y es quizás una consecuencia del éxito obtenido por la novela.

En esos años, y muy particularmente en el 78 (quince años después de la publicación) Cortázar narra varias veces la escritura en entrevistas de cierta repercusión. Las numerosas páginas dedicadas al tema retoman algunos elementos que ya figuraban en las cartas del período 1958-1963, aunque sus declaraciones resultan ahora programáticas (cómo hay que leer la novela) y son olvidadizas o simplificadoras. Pero sobre todo cambia el punto de partida: es otro capítulo, el capítulo "del tablón", el supuesto punto de arranque. Por ejemplo, sobre el comienzo de Rayuela, le declara a Ernesto González Bermejo en 1978 :

Empecé por una especie de obligación de empezar. Al principio fueron papelitos que había ido escribiendo de diferentes modos, en diferentes momentos y después todo 
eso se ajustó y se combinó.

El primer capítulo que escribí fue el del tablón. En la máquina, la novela empezó ahí, en la parte de Buenos Aires [...] Le podría señalar capítulos que son, por ejemplo, pequeñas descripciones, ambientes, situaciones de París que se insertaron luego naturalmente en la novela; es decir, que habían sido pedazos de la novela sin que yo lo supiera (Cortázar 1991 : 774).

El cambio, con tan pocos años de diferencia, es sorprendente. "La araña" deja de ser el punto de partida de una "voluntad de novela" y el momento en que la escritura se "da", se dispara en un tirón afirmativo, para convertirse en uno de esos "papelitos" escritos de "diferentes modos". Ahora, lo que aglutina, es el envión de escritura del capítulo "del tablón". Se refuerza así la idea de un comienzo preciso en donde la búsqueda, la incertidumbre, la falta del punto de arranque, las múltiples reescrituras de finales antes de los principios, se reducen a la espera de una revelación o un don; se comienza por obligación y se continúa gracias a un envión enigmático. La escritura empieza de manera decidida y ahí se ordena lo anterior, esos "capítulos cortos" escritos, a diferencia de este nuevo capítulo, sin "ninguna intención de novela". Nótese que la "intención" parece hecha, repito, de voluntad, no de proyecto (la voluntad es el proyecto), ya que tanto "La araña" como el capítulo "del tablón" son, en ambas versiones, escrituras volcánicas, repentinas, que inducen una escritura de largo alcance pero que sigue sin saber adónde se dirige.

Por otro lado, se elimina por segunda vez "La araña" (la primera, de la novela ; ahora, del relato), para focalizarse en otro capítulo, un capítulo brillante que cristaliza poética y temáticas del texto (puente, cotidianeidad cruzada con lo legendario, yuxtaposición de Eros y Tánatos, desdoblamientos espaciales e identitarios, etc.). Al condensar temáticas, tonos y referencias textuales comunes a toda la novela, puede tomárselo como un anuncio o una prefiguración del conjunto, lo que corresponde con los valores legendarios atribuidos al origen, vale decir, al origen en tanto que episodio determinante de lo que sigue : aunque la escritura haya empezado "por cualquier parte" o por "varias partes a la vez", aquí se restaura la función fundacional de la primera página. "La araña" introducía una situación sexual explícitamente perversa entre Talita y Traveler ; entre un comienzo y el otro pasa algo que se parece a una censura, o sea una vuelta "más acá" de lo que el mismo Cortázar llamaba sus "límites". Ultima ventaja "del tablón": forma parte de la novela, o sea que reordena cronológicamente el material, introduciendo un "nuevo" comienzo que invitaría a otras lecturas.

En una perspectiva similar, nótese la vehemencia con la cual en las entrevistas y textos aledaños Cortázar le agrega a la idea de ruptura literaria un valor social contestatario. Rayuela, afirma, tenía objetivos ambiciosos, los de atacar a instituciones, al pasado, a las tradiciones:

¡Ah! Ése es uno de los cócteles molotov que yo tiro en Rayuela. Y se lo tiro a toda una clase social y a una estructura intelectual de raíz hispánica (Cortázar 1991: 771).

¡Un ajuste de cuentas del carajo! En primer lugar, como le decía, es una puesta en duda de todos los valores. Ahí, freudianamente, estoy matando a toda mi familia, esto matando a mi país, a mis compatriotas, a mis amigos, estoy matando todas las herencias (772).

En Rayuela el hombre nuevo es, ante todo, el escritor nuevo, que rompe con toda herencia y prefigura la conversión revolucionaria posterior. 
21 Por último, conclusión o no del relato, recordemos, que en 1982, Cortázar vende a la Universidad de Texas en Austin el dactilograma de Rayuela, asegurando así, él mismo, la correcta conservación de ese material.

\section{Bitácora : el otro libro}

El gesto, tan prematuro, de regalar el cuaderno de anotaciones es sorprendente. Para ponerlo en perspectiva, recordemos que Barrenechea es una crítica con la que Cortázar mantiene, alrededor de 1960, una relación privilegiada: ella le manda artículos sobre literatura fantástica o clases sobre sus propios cuentos (Cortázar 2012 : 132, 210), no duda en discutir aspectos que no la convencen en tal o cual texto, o que inclusive emite juicios globalmente negativos (como sucedió con Los premios). ${ }^{2}$ Una crítica que se convierte a la vez en una figura protectora, en primera destinataria y en una autoridad respetada, si no temida. Finalmente, la correspondencia muestra cómo Barrenechea termina convirtiéndose en cómplice, en un dispositivo de identificaciones : en su reacción a la reseña publicada en Sur en 1964, el escritor califica el texto de "crítica definitiva", considerando que en tanto que escritor "tiene la suerte de que alguien como vos sea él" y diga la cosas "exactamente en el orden en que [él] las hubiera dicho" (507). Los códigos del Cortázar se han convertido en códigos compartidos, estamos de nuevo en la cercanía de libros y afectos.

La edición del cuaderno, efecto tardío del regalo, tiene lugar entonces en 1983. La fecha y el lugar no son anodinos, ya que se trata, a los veinte años de la primera publicación y en la misma editorial (Sudamericana), de proponerle al público una inhabitual "continuación" de la novela. Se incluye en ella, además del cuaderno cuatro capítulos inéditos (entre ellos, "La araña"). Detrás del libro leído, tan conocido y considerado como "múltiple" hay -había -, otro libro, que ahora se descubre: la escritura de Rayuela se prolonga, las opciones y saltos de texto a texto se multiplican. Tampoco es inocuo el nombre elegido : "Cuaderno de bitácora", es una expresión utilizada por Cortázar y que metaforiza el proceso de escritura como viaje, inscribiéndolo en una tradición que ennoblece el documento y el proceso allí evocado. De más está decir que la navegación, lo imprevisible, el encuentro fortuito sugeridos, están en relación con las características de Rayuela, también en su movimiento hacia un territorio utópico, por lo que el libro publicado pasa a ser una etapa más de ese viaje iniciado en el cuaderno (o, por qué no, en el barco de Los premios).

En términos de crítica genética, el trabajo de Barrenechea es precursor por la utilización matizada de las herramientas de esa disciplina reciente. Su objetivo es comentar el cuaderno y no necesariamente estudiar todo el dossier genético posible (lo que sí hace Danielle Constantin). Por ello la crítica toma el cuaderno como un diario, si no exhaustivo, representativo del conjunto del proceso : como un documento pleno de sentido que puede servir para comprender la historia de una escritura. No se interroga por ejemplo sobre el proceso en sí de textualización (los diferentes borradores, modos de corrección, etc.), en la medida en que el material propuesto no lo permite, a pesar de que Cortázar aludía a una redacción profusa y repetida de ciertos episodios. Su perspectiva está por lo tanto delimitada por el contenido de ese documento, es decir por el regalo.

Desde otra perspectiva nótese que Barrenechea no lo transcribe (opción elegida en la edición Archivos del 91) sino que lo reproduce : privilegia por lo tanto su visualización a 
su lectura. Por supuesto, las singularidades de distribución de las frases y la presencia de dibujos justifican esta preferencia, que hubiese podido limitarse a algunas páginas significativas. La solución radical elegida tiene que ver más con la puesta de relieve del objeto, si no con su fetichización, y es quizás una decisión del editor, pero en todo caso convoca a la autoridad de Cortázar -a la mano de Cortázar - en el texto. Subrayemos también que el estudio genético y la edición propuesta se prolongan en la edición Archivos con la inclusión de un dossier genético más completo (se incorporan seis capítulos desechados por Cortázar y consultables en Austin), la transcripción del Cuaderno de bitácora, y un nuevo estudio de Barrenechea sobre la génesis de la novela ("Génesis y circunstancias") (551-570), que en realidad retoma de manera sintética las conclusiones del estudio de 1983, agregándole comentarios a partir de un nuevo material al que tuvo acceso, a saber las cartas de Cortázar a su editor, Francisco Porrúa, y también ampliando las hipótesis hacia una lectura general de la novela que, explícitamente, alude a su reseña publicada en Sur en $1964 .^{3}$

Barrenechea parte entonces de la cronología del cuaderno como base y del principio de intencionalidad o proyecto como elemento determinante. 0 sea que plantea ella también la pregunta del inicio, del primer paso en la textualización, organizando una cronología de la escritura que pasa por alto las 38 primeras páginas ("el cuaderno empieza en la página 39 con la redacción de la novela") (21), páginas en donde figuran materiales varios, en particular dos comienzos frustrados de relatos, unas reflexiones ensayísticas (sobre la pérdida de la "poesía" en Occidente así como la de la búsqueda de un Centro, y sobre el privilegio dado a lo racional en literatura, con críticas explícitas a Robbe-Grillet), y por fin dos relatos de sueños. No deja de ser problemática esta exclusión, en particular la reflexión sobre el nouveau roman que era, en ese momento, el gran movimiento de renovación de la novela en Francia, ante el cual Cortázar se sitúa en disidencia, privilegiando entonces una novela de expresión afectiva y trascendente, como lo será Rayuela. ¿En qué medida y por qué esas reflexiones no forman parte de la definición de la "intención" de escritura arriba señalada? Razonamientos análogos podrían llevarse a cabo sobre otros textos excluidos.

Para ella entonces la "primera página" es aquélla en donde figura el título "Novela" y el esquema de lo que será el capítulo "La araña", más algunas indicaciones para episodios posteriores. Sin embargo, inmediatamente, afirma que uno de los sueños que preceden el comienzo del cuaderno "se incorpora luego a Rayuela" (21). La ambivalencia es el resultado de la búsqueda de esa "primera página"; en realidad, respetando los términos de proceso de escritura y gracias al material disponible, ella identifica un doble comienzo : uno de los sueños, el que pone en escena una confluencia entre París y Buenos Aires, transcrito justo antes de dibujos y algunas anotaciones sobre el capítulo "La araña" (que serían el segundo arranque entonces). Barrenechea los califica, respectivamente, de "matriz" al sueño (en tanto que forma o modelo) y "núcleo generador" al capítulo (por su capacidad de desarrollo) (22 y ss.). La respuesta a la pregunta del comienzo, matizada, elude el obstáculo de un origen único o punto absoluto, desdoblando el inicio entre lo que sería un modelo o esquema inspirador y una textualización que permite lanzarse en la escritura. O sea que, como en la versión publicada de Rayuela, en donde la novela empieza de alguna manera dos veces (capítulo 73 y capítulo 1), el proceso aquí también tiene dos puntos de partida, según la distinción eficaz entre matriz (el sueño) y núcleo generador (el capítulo). 
otro lado, en un análisis pormenorizado del capítulo "La araña", ella encuentra en ese texto los elementos centrales de la novela por escribirse, o si se quiere, las líneas que van a desplegarse a partir de ese principio :

"La araña" encierra en sí, desde que empieza a gestarse la novela, todo lo que va a desplegarse en ella: Eros-Thánatos, erotismo-escritura, erotismo-escrituramandala, pasaje, busca de un centro, impulso de trascendencia, caos-cosmos, desintegración-unidad, figura (22). Y sin embargo, dice, ese capítulo va a "sobrar" y ser eliminado "por razones misteriosas" (25). Sea como fuere, habría desde el comienzo una fuerte "presencia de lo trascendente (...) Unida a ello está la presencia de la escritura (la desescritura) como camino a la trascendencia, como experimento y busca" (22). De allí, va a surgir el segundo capítulo nodal, el del tablón, agregándole a lo que precede la idea de pasaje. Enseguida después, emerge la idea del Mandala (22-23), es decir lo que completa el pasaje con un aporte místico : el "centro". Todos estos elementos son considerados como generadores (24). En particular, le atribuye una importancia central al capítulo de "los hilos" (cap. 56) que retoma aspectos de "La araña", o sea que es el que lleva la huella del primer texto descartado.

Este análisis recorre con un rigor las anotaciones de Cortázar, viendo en ella elementos temáticos de carácter formal -lo que vuelve convincentes las conclusiones -, eligiendo un modelo de exposición cronológico, y por lo tanto narrativo, siguiendo las prácticas habituales de la crítica genética. Después del relato exaltado, variable, del propio autor, Barrenechea construye otro relato, otro comienzo, paralelo y coherente, con otra autoridad: la del estudio sistemático y lógico del material prerredeccional existente. Queda el interrogante del por qué y para qué esa repetida pregunta del comienzo, es decir si un texto como Rayuela, repitámoslo, se adapta a un cuestionamiento de ese tipo.

31 Un tercer aspecto que vale la pena señalar si se contrapone el relato del escritor y el análisis de Barrenechea es lo que concierne el cambio, la ruptura, la búsqueda de una novedad. En esa perspectiva, las anotaciones del cuaderno confirman y matizan al mismo tiempo las afirmaciones anteriores de Cortázar, ya que señalan lo tardío del abandono del repertorio temático de los cuentos. La tentación de incluir elementos fantásticos en la novela (lo que la emparentaría entonces con esa tradición genérica), estuvo muy presente durante el proceso. Barrenechea señala la importancia del enlace topológico entre dos espacio-tiempo diferentes en la obra de Cortázar y en Rayuela, enlace resuelto de manera distinta en la novela. Porque la búsqueda de confluencia, gran tema de trabajo en el cuaderno, presupone borrar idea de precedente, causa, comienzo, cronología, representando una forma de simultaneidad después de todo afín con lo fantástico (38-43). Todo esto, que podría verse como una puesta en duda de la novedad absoluta, lleva a una doble mirada, a un gesto heroico de ruptura y a la prefiguración del futuro :

Cortázar, especie de Jano que mira al pasado y al futuro, y que lucha por desprenderse de ese pasado como se ve en el proceso de El cuaderno. La cara del pasado es una forma genérica y su retórica, me refiero al relato fantástico del que renegaba [...] o la búsqueda del alejamiento del tipo de escritura de los cuentos, ese abandono de "esa especie de 'vert paradis des amours enfantines' ". La cara del futuro era la busca de una figura, concreción de la unidad y de la plenitud, reveladora del misterio, que ya asomaba en símbolos de los primeros cuentos (43).

La lectura tiende a probar, con otros argumentos, la novedad de Rayuela con respecto a lo anterior y el desprendimiento de Cortázar de la literatura fantástica y del cuento. Una ruptura que es una verdadera fundación, llevada a cabo progresiva, heroicamente, si 
seguimos la cita precedente. En el artículo incluido en la edición Archivos, ella refuerza la idea de una "ruptura", atribuyéndole a la novela un valor de parte-aguas, y para probarlo rastrea sus efectos (en particular la idea de "figura") en 62, modelo para armar, en los libros misceláneos (La vuelta al día en 80 mundos y último round) y en El libro de Manuel (562) Estas afirmaciones pasan por alto las tres novelas ya escritas por el autor en esa fecha y que prefiguraban a su manera la representación de un grupo humano y un tipo de acción, sobre todo en El examen y Los premios; así como excluyen del panorama los cuentos posteriores, en particular los de Todos los fuegos el fuego (de 1966), quizás los más brillantes escritos por Cortázar, y en los que la confluencia de dos espacio-tiempo está retomada desde la tradición de lo fantástico. Por otro lado, si volvemos al comienzo, podría pensarse que los cuentos son también el punto de inicio, ya que son eso a partir de lo cual se reescribe, desechándolo progresivamente. En ese sentido, todo comienzo es "romper" y "repetir" al mismo tiempo. Sin embargo, el análisis de la génesis pone el acento en determinar la emergencia progresiva de lo nunca visto, de la ruptura y el cambio, en vez de marcar, a contrapelo de los discursos del autor, una continuidad. De todos modos es notable la manera en que Barrenechea (y ante todo Cortázar, claro está) pasan por alto las tensiones del proyecto renovador de Rayuela perceptible en el proceso en sí de escritura, tomando al pie de la letra las declaraciones de intención sin cotejarlas con su cristalización textual. Un ejemplo sería el carácter convencional de la definición de personajes (sobre el que hay muchas anotaciones en el cuaderno) y que Barrenechea estudia en detalle, lo que presupone una concepción clásica de esa instancia central en el relato.

33 Consecuentemente, se puede afirmar que el estudio de Barrenechea tiene dos vertientes. Por un lado genético. Por el otro, establece un diálogo con declaraciones del escritor o en todo caso los análisis críticos las prolongan, en otro plano y con otros instrumentos. Los dos relatos (el del autor, el de la crítica) coinciden en lo fundamental : no se trata sólo de romper con la tradición ni de innovar ("Es indudable que el impulso inicial de la novela llevaba en sí el germen de la producción de un texto de ruptura" escribe Barrenechea) (1991 : 566), sino de construir un jalón fundacional, una articulación que permita abrirle al brillante escritor de cuentos fantásticos el espacio de audaz novelista experimental que, pronto, será el gran escritor comprometido. Porque la emergencia de lo revolucionario como resultado de Rayuela está también sugerida en los textos de Barrenechea: "En Cuaderno y la misma Rayuela abundan en pasajes dedicados a la subversión que Cortázar quería instaurar tanto en la vida como en la escritura" (1991: 566). No es sorprendente, por lo tanto, que ella termine el artículo del 91 con algunas referencias a las posiciones políticas del autor durante la escritura de Rayuela, lo que tiende a validar este otro aspecto del relato, cerrando el círculo de la determinación instaurada por la fundación y el origen.

La lectura de Barrenechea amplifica y le da fundamento entonces al propio discurso de Cortázar: se vuelve su "intérprete" (fenómeno absolutamente corriente en la crítica cortazariana de los 80). El "puente" entre ellos, reestablecido en el 63 con la publicación de Rayuela y el regalo del cuaderno, no ha dejado de funcionar y de ser recorrido en ambas direcciones. 


\section{La lectura utópica}

Rayuela, novela que se quiere abierta y autorreflexiva, que en vez de una acción delimitada y un mundo unívoco, incluye más bien la acción de un comentario y sobre todo el comentario de una acción, decía Cortázar (1967: 39), esa novela, entonces, se prolonga fuera del libro, en los documentos prerredaccionales dados a conocer progresivamente, en los relatos sobre motivaciones, estados de ánimo y pasos de su creación, en la exaltación por la recepción juvenil, todo lo cual, en un movimiento pendular, redefine el sentido del texto. Cortázar es un escritor cuya imagen está marcada por la tradición de la literatura fantástica y la de los relatos breves; por lo tanto, la producción de un texto como Rayuela, que en realidad se inscribe en una serie de intentos novelísticos anteriores (sus tres novelas ya escritas, de las que sólo logró publicar una) ${ }^{4}$ y en un mapa de lecturas bien establecido (el surrealismo, Macedonio Fernández, el existencialismo), exige una reorientación de su perfil de escritor. Lo cual pasa por actualizar paradigmas vanguardistas e integrar el aire de libertad que ya empezaba a flotar en la vida intelectual francesa de fines de los 50 (piénsese, por ejemplo, en los primeros textos de Barthes y en los ensayos de Natalie Sarraute o en los de Michel Butor, sin olvidar, de nuevo, el ensayo-manifiesto de Robbe-Grillet, "Por una nueva novela").

Porque desde el regalo del Cuaderno de bitácora a las declaraciones al final de su vida sobre la escritura de Rayuela y a la venta de sus papeles a Austin en el 82, se va construyendo un relato que le da una fuerza fundacional y de ruptura, no sólo al libro, sino también a su escritura. Las condiciones de creación y las características del proceso, redoblan y amplifican el sentido del texto, fijando orientaciones de lectura: novedad absoluta, ruptura con lo fantástico, gesto fundacional en relación con lo que sigue literariamente 62, modelo para armar - y políticamente -descubrimiento de lo "humano", que llevaría a Cuba-. El relato es en muchos puntos contradictorio pero tiende entonces a retomar la figura de autor, atribuyéndole intenciones y peripecias que permiten conciliar elementos dispersos en una figura coherente, reforzando por lo tanto su eficacia en el acompañamiento del texto.

A todo esto podría oponérsele otro relato, un relato que nos cuente que el origen es inhallable, que las obras no comienzan, o no comienzan en el sentido legendario, bíblico, del término. Que no hay un big bang ni un paso de la nada al universo, de la oscuridad a la luz. Que los textos empezaron ya en otros textos, propios o ajenos, antes del comienzo, antes de que la idea de un objeto de escritura posible haya surgido en la mente del autor. Que nos cuente también que el comienzo es una cuestión de elección (un allí, un entonces) que, en tanto que hito, convierte a lo anterior en antecedente y a lo posterior en consecuencia. Que nos cuente que el origen, al ser un relato, se modifica, se deforma, se reescribe; que el origen es siempre una delimitación de sentidos realizada posteriormente -siempre se está después, siempre se está alejado del origen - ; como en el caso arquetípico de la autobiografía (Bourdieu); el comienzo es el lugar que anuncia y explica lo que se es hoy. Y que cuente, por fin, que a pesar de la relatividad de todo esto, de la imposibilidad de acceder a una verdad plena sobre el origen o a un relato único y estable, cierto es que la profusión, la voluntad de escritura y la inestabilidad permiten comenzar y dar la mejor prueba de que se ha comenzado: la publicación de un libro terminado. El origen, decía Benjamin, es un torbellino en el río del devenir (43-44). En el impulso de escritura, el origen es ese leve movimiento que perturba la superficie de un

Cuadernos LIRICO, 9 | 2013 
torrente discursivo. Según el mito, como lo afirmaba Foucault, en el origen estaría la perfección, la pureza y la verdad, cuando en realidad, allí está el error, el descubrimiento que las cosas no comienzan y que lo que hay "antes" siempre se caracteriza por la mezcla y lo heterogéneo (1971a : 1006-1007).

Sin embargo, de manera insistente, la pregunta del comienzo le es planteada a Rayuela, primero por el escritor, después por una crítica que en alguna medida refleja y profundiza su discurso, esbozando otro u otros relatos. Dos comienzos, en realidad. Ante todo, el del inicio de la escritura, el de la página inaugural a la vez reveladora y determinante, ese núcleo en el cual encontraríamos condensado todo lo que sigue. Resulta extraño, como dijimos, partir en el caso de Rayuela del interrogante del comienzo. Desde ya, en un libro que incluye y exhibe mecanismos de creación y postulados extremos de organización, uno de los puntos más espectaculares de puesta en duda del orden es el comienzo : no sólo por el conjunto de paratextos (el célebre "Tablero de dirección", la inclusión de dos epígrafes de tonalidad radicalmente opuesta) o por los dos capítulos que cumplen la función de comienzo (uno de tonalidad poético-programática y otro, mucho más acorde con las funciones novelescas y con la tradición formal de los íncipits), sino sobre todo por el inicio de ese primer capítulo, que lleva el número 73, nada menos, y que empieza, como es sabido, por "Sí, pero..." ("Sí, pero quién nos curará del fuego sordo, del fuego sin color que corre al anochecer por la rue de la Huchette...") (314), lo que lo incluiría en la serie de íncipits que rechazan el gesto de comienzo, que fingen situarse en un discurso o en una discusión anteriores, tal cual lo hizo Foucault en El orden del discurso, o que exhiben el artificio (Foucault 1971b, Del Lungo). La novela desdibuja el inicio, rechaza el corte radical del comienzo, ese gesto de fundación, para inscribirse entonces en un flujo, en un continuo discursivo, en un movimiento dinámico de corte vanguardista. ${ }^{5}$

Por lo tanto, el comienzo de la novela tal cual se publica sería isomorfo del proceso de escritura, reflejando su inestabilidad, su variabilidad, su carácter de búsqueda (o de navegación, si seguimos el título del Cuaderno de bitácora). De hecho, los textos más antiguos que incluye el libro son esos fragmentos sobre París que Cortázar escribe en el 51 y que aparecen en los capítulos 8 y 132 de la novela editada ; sin embargo, es difícil decir que la redacción empieza allí, ya que la integración de textos escritos antes de que emergiera el proyecto tiene que ver con un mecanismo de desplazamiento y reciclaje que, precisamente, va a definirse recién en el período 1958-1963, y que se constata en la inclusión de una especie de "diario de escritura" o "diario de lecturas" (noticias de diarios, avisos publicitarios y citas de otros libros). En este caso, se trataría de un autorreciclaje, autodesplazamiento. De nuevo, podría pensarse que lo que cuenta es la idea que rige la organización y no la autoría de tal o cual fragmento (ya que la organización prevé la asimilación de textos de otros autores). 0 , al menos, la escritura, en este caso, es tanto una textualización como una disposición (si no un dispositivo). En última instancia, el comienzo de la escritura no estaría en el primer texto, sino en el primer gesto de ubicación de algo alrededor de una idea-núcleo. Si escribir es ordenar y disponer, un borrador no es una primera textualización (ni "La araña", ni "el tablón"), diferente de la definitiva, sino un conjunto en el que figuran fragmentos que "encontraron su lugar". Una genética "escenárica" o prerredaccional correspondería mejor con este ejemplo que una "de la inscripción" o redaccional (Lois 21).

40 El otro comienzo planteado gira alrededor de la idea de una novedad, de una ruptura, de un salto a otra cosa. La insistencia con la rebelión, la subversión, la escritura a contracorriente, funciona como un discurso utópico que actualiza constantemente un 
libro ideal, un libro imposible que terminaría con todos los libros, con todas las limitaciones, que abriría espacios de libertad y de creatividad inéditos. Porque es evidente que las afirmaciones de Cortázar superan con creces la explicación del surgimiento de un texto dado y de sus sentidos digamos "inmanentes". A lo escrito y sus exigencias, sus imposiciones, sus valores, se le adjunta otra dimensión. Algo que cabría denominar un imaginario de creación, el del Yo ideal que proyecta en lo que produce un horizonte soñado en donde se identificaría un "resto" inexpresable y que lleva a seguir escribiendo infinitamente. "Valgo más que lo que escribo", diría Barthes al respecto en La preparación de la novela (207-221). Esta novela imposible (antinovela, antilibro, espacio antinormativo de libertad y de ruptura radicales) es por supuesto una ficción, que no sólo no corresponde con el funcionamiento de Rayuela, sino, seguramente, no podría funcionar con ningún libro. Es lo que percibe Barrenechea en su lectura de las cartas cuando el escritor corrige las pruebas de galera y "no se resigna a que traicione la imagen ideal que de ella se ha ido forjando y que quiere que el lector reconozca" (Cortázar 1991: 566). Las declaraciones de Cortázar sobre la emergencia de la novela anhelan restaurar, dar a conocer, esa "imagen ideal" ya forjada, como vimos, y que podría ser traicionada por el libro real. De hecho, entonces, esto supone prolongar la escritura, en el sentido de prolongar el deseo que la originó y la experiencia de su emergencia, exponiendo el deambular creativo como mecanismo evocador de la Obra inalcanzable (Starobinski 481-484). Y, valga una concesión a la supuesta determinación del origen; en su primer libro de cuentos, La otra orilla, inédito hasta 1995, Cortázar preveía incluir un liminar escrito en 1945 que terminaba así : "Las doy [a estas historias] en libro a fin de cerrar un ciclo y quedarme solo frente a otro menos impuro. Un libro más es un libro menos; un acercarse al último que espera en el ápice, ya perfecto" (Cortázar 2008 : 13). El relato de génesis o la primera incursión en los cuentos lanzan un movimiento imaginario, paralelo a la escritura y que la proyecta hacia ideales que la superan.

41 Este relato acompaña duraderamente la recepción, en la cual también una lectura imposible, lúdica, libre y creativa (la que sueña el yo ideal del receptor) va a enmarcar los sentidos e inscribirse en los intersticios de la letra concreta del libro. Un libro que puede leerse entonces como el avant-texte de otro, un libro inexistente y que, sin embargo, el lector parece "reconocer". Digamos que una dimensión quimérica, un relato utópico se entremezcla entonces con la creación de Rayuela, tiñendo la textualización y orientando sus valores, en particular gracias a la vehemencia con la cual el propio Cortázar los expresa, confundiendo en tonos y tipos de afirmaciones el discurso literario, el metaliterario y el íntimo: Barrenechea hablaba al respecto de una "pedagogía", que es constante y programática (Barrenechea 1983 : 22). Las ampliaciones, recurrencias y en algunos casos revisiones del relato de esta "aventura de escritura" constituyen la historia de la novela hasta nuestros días, forman parte de sus logros más fuertes, y no son ajenas a su fenomenal éxito. Una historia que conlleva la paradoja de sacralizar una materia textual y una figura del autor, gestos que, claro está, entran en tensión con los cimientos de esa utopía liberadora y antiautoritaria.

Porque la introducción de la esfera genética por Barrenechea, tanto en su análisis que posee la autoridad del saber crítico como en la reproducción facsímil del manuscrito, es decir en la exposición de mecanismos, etapas e intermitencias del proceso de escritura, viene a reforzar la autoridad del escritor y el prestigio del texto. A la revolución formal, al rechazo subversivo, a la negatividad, lo genético le restituye la nobleza del trabajo, la exigencia de la corrección, la creencia en la forma expresiva, la adhesión a una eficacia 
psicológica y discursiva de los personajes, la búsqueda de una transmisión de experiencias y conocimientos : una especie de teleología o, si se quiere, una auctoritas nueva ${ }^{6} \mathrm{O}$ sea, si Rayuela debía ser un simple patchwork de fragmentos dispersos con una poética negativa, el contrapunto entre la forma elegida y ciertos modelos novelísticos canónicos, se desdibuja o se vuelve más complejo cuando aparece en escena un personaje insólito : el del escritor peleando por la expresión, interrogándose sobre la forma, corrigiendo el término abusivo, limitando y reconstruyendo a cada paso un proyecto que, incluso en su descontrol, forma parte de lo previsto. Publicar los documentos pre-textuales de obras modernas es prolongar una tradición de gran escritura, es reivindicar filiaciones sorprendentes, y también, como el caso de Cortázar lo demuestra, es intentar asegurarse una comunicación literaria lo más eficaz posible, gracias a una figura de autor renovada.

\section{BIBLIOGRAFÍA}

AAVV. Carnets d'écrivains. Paris : CNRS, 1990.

Barrenechea, Ana María. “La estructura de Rayuela de Julio Cortázar” (1968). Textos

hispanoamericanos. Caracas : Monte Avila, 1978. 195-220.

Barrenechea, Ana María, Cortázar, Julio. El cuaderno de bitácora de Rayuela. Buenos Aires :

Sudamericana, 1983.

Barthes, Roland. La préparation au roman I et II. Paris : Seuil, 2003.

Benjamin, Walter. L'Origine du drame baroque allemand. Paris : Flammarion, 1985.

Biasi, Pierre-Marc de. La génétique des textes. París : Nathan, 2000.

Boie, Bernhild, Ferrer, Daniel. « Les commencements du commencement ». Genèses du roman contemporain : incipit et entrée en écriture. Bernhild Boie y Daniel Ferrer (eds.). París : CNRS Ed., 1993. 7-36.

Bourdieu, Pierre. "L'illusion biographique ». Raisons pratiques. Sur la théorie de l'action. París : Seuil, 1994. 81-90.

Broichhagen, Vera. "Julio Cortázar o las barbas del diablo". Cuadernos LIRICO, 7 | 2012, consultado el 16 de mayo de 2013. URL : http://lirico.revues.org/595

Constantin, Danielle. Masques et mirages. Genèse du roman chez Cortázar, Perec et Villemaire. New York : Peter Lang, 2008.

Cortázar, Julio. Rayuela (1963). Edición de Julio Ortega y Saúl Yurkievich. Madrid : Archivos, 1991. Cortázar, Julio. "De la impresión de no estar del todo". La vuelta al día en ochenta mundos. México : Siglo XXI, 1967. 32-42.

Cortázar, Julio. La otra orilla (1995). Madrid : Punto de lectura, 2008.

Cortázar, Julio. Papeles inesperados. Buenos Aires : Alfaguara, 2009.

Cortázar, Julio. Cartas 1955-1964. Madrid : Alfaguara, 2012. 
Del Lungo, Andrea. L'incipit romanesque. Paris : Seuil, 2003.

Giordano, Alberto. "Cortázar en los 60 : ensayo y autofiguración”. Modos del ensayo. Rosario : Beatriz Viterbo, 2005. 169-178.

Mata, Oscar. "El cuaderno de bitácora de Rayuela". Casa del tiempo, vol. VII, época III, n 80, septiembre 2005, n 80 (34-36). URL :http://www.uam.mx/difusion/ casadeltiempo/80_sep_2005/34_36.pdf

Foucault, Michel (1971a). « Nietzsche, la généalogie, l’histoire ». Dits et écrits. Volume I 1954-1975. Paris : Gallimard. 1004-1025.

Foucault, Michel (1971b).L'ordre du discours. Paris : Gallimard, 1971.

Gunn, Daniel. Analyse et fiction. Aux frontières de la littérature et de la psychanalyse. Paris : Denoël, 1990.

Lois, Elida. Génesis de escritura y estudios culturales. Introducción a la crítica genética. Buenos Aires : Edicial, 2001.

Ricœur, Paul. « Regards sur l'écriture ». La naissance du texte. Edición de Louis Hay. París : José Corti, 1989. 213-220.

Starobinski, Jean. «La perfection, le chemin, l'obstacle ». Starobinski en mouvement. Murielle Gagnebin y Christine Savinel (eds.). Seyssel : Champ Vallon, 2001. 471-492.

Said, Edward W. Beginnings. Intention \& method. New York : Columbia University Press, 1985.

Sarlo, Beatriz. "Releer Rayuela desde el Cuaderno de bitácora". (1985). Escritos sobre literatura argentina. Buenos Aires : Siglo XXI, 2007. 246-259.

\section{NOTAS}

1. Por ejemplo, en 1974, afirma que el libro, escrito para "cuarentones", no tuvo la recepción esperada: "Pero entonces, sorpresa. En esos diez años de que hablo, Rayuela fue leída por incontables jóvenes del mundo, muchísimos de los cuales serán ya parte en esa lucha que yo sólo vine a encontrar al final. Y mientras los 'viejos', los lectores lógicos de ese libro escogían quedarse al margen, los jóvenes y Rayuela entraron en una especie de combate amoroso, de amarga pugna fraterna y rencorosa al mismo tiempo". En la conclusión del texto la ruptura se amplía : "A ese cielo, y eso que nos une, ellos y yo le llamamos revolución" (2009 : 174-175).

2. Tres citas sacadas de la correspondencia : "Soy moderadamente célebre en Latinoamérica. Así dice por lo menos mi editor -y Anita Barrenechea, ángel si los hay" (199) ; "Vale la pena escribir para alguien que penetra tan intensamente en una obra : es una recompensa real" (210) ; "Los palos que pueda pegarme Anita [sobre Rayuela] no serán productos de envidia o resentimiento [... ] ; y habrá, además, un serio intento de hacer una cross-section del libro y analizarlo de verdad" (470).

3. Comentario al margen de orden general : la importancia dada a los detalles en la historia de los cuadernos o la precisión del estudio de su contenido, tanto como el tipo de edición, son directamente proporcionales al lugar ocupado por el escritor del que se trata en el canon y por la concepción de escritura que se le atribuye. En ese sentido, Proust y Flaubert, sin ir más lejos, merecen trabajos mucho más minuciosos que otros. Por ejemplo, se analizan en Proust marcas estilísticas en las notas de las libretas (uso de frases nominales, tiempos verbales o paralelismos retóricos) (AAVV). 
4. El examen fue rechazada por Victoria Ocampo (Cortázar 2012 :147) y enviada sin éxito a algún concurso literario (165), mientras que Cortázar le propuso en vano a Miguel Antín filmar Divertimento (287-288).

5. Bernhild Boie y Daniel Ferrer exponen la diferencia existente entre el comienzo de la obra y el comienzo de la escritura, diferencia que abre una falla entre el tiempo de lo escrito y el tiempo de la inscripción, entre el espacio de la obra en tanto que objeto y el espacio de la obra en tanto que campo de trabajo (8).

6. Ricœur afirma que se puede ver la divulgación de los pre-textos de dos maneras distintas. Por un lado, ésta convertiría a la superficie lisa y uniforme del texto definitivo en un conjunto fracturado, fragmentado, hecho de vaivenes, dudas. Pero se la puede ver, al contrario, como un hecho que le da una autoridad nueva a la versión final : ya no es un fruto casual, sino que es la última etapa de una serie motivada: "la compréhension de l'histoire du texte derrière le texte nous restitue un texte final plus riche que les textes mis en miettes par la critique" (217).

\section{RESÚMENES}

El artículo estudia el proceso de escritura de Rayuela a partir de las diferentes declaraciones de Julio Cortázar y del estudio genético llevado a cabo por Ana María Barrenechea. Se trata de comprender la función de los relatos entonces construidos, del valor de la edición de materiales preparatorios (el Cuaderno de bitácora) y las características de la interacción del autor con la investigadora argentina.

L'article étudie le processus d'écriture de Marelle à partir des différentes déclarations de Julio Cortázar et de l'étude génétique réalisée par Ana María Barrenechea. Il s'agit de mieux comprendre la fonction des récits alors construits, de la valeur de l'édition des matériaux préparatoires (le Cuaderno de bitácora) et des caractéristiques du dialogue de l'auteur avec la chercheuse argentine.

The article examines the writing process in Marelle from different statements of Julio Cortázar and a genetic study by Ana María Barrenechea. This is to better understand the function of the stories that were written, the value of publishing the preparatory materials (Cuaderno de bitácora) and the characteristics of the dialogue between the author and the argentine researcher.

\section{ÍNDICE}

Mots-clés: Origines, critique génétique, manuscrits, figures d'auteur, Marelle

Keywords: Origins, manuscript, Genetic criticism, Hopscotch, author's figure

Palabras claves: Orígenes, crítica genética, manuscritos, figuras de autor, Rayuela

\section{AUTOR}

\section{JULIO PREMAT}

Université Paris 8 
Ju.premat@wanadoo.fr 